\title{
The effects of feeding a high-fiber or high-starch pellet at two daily allocations on feed intake patterns, rumen fermentation, and milk production of mid-lactation dairy cows
}

\author{
J. Haisan and M. Oba* (1) \\ Department of Agricultural Food and Nutritional Science, University of Alberta, Edmonton T6G 2P5, Canada
}

\begin{abstract}
The objective of this experiment was to determine the effect of pellet type and feeding amount on feeding behavior, dry matter intake, rumen fermentation, and milk production of lactating dairy cows. An experimental diet was formulated to provide an adequate amount of nutrients to a $650-\mathrm{kg}$ cow producing $40 \mathrm{~kg}$ of milk per day, with a portion of the diet removed as a highfiber $(33.2 \%$ neutral detergent fiber; F) or high-starch ( $56.8 \%$ starch; S) pellet. Pellets were fed at a low $(1 \mathrm{~kg}$; L) or high $(3 \mathrm{~kg} ; \mathrm{H})$ amount twice per day alongside a partial mixed ration (PMR). Four complementary PMR were formulated for each pellet treatment such that the overall diet (pellet + PMR) offered to the cows was the same among all treatments. Eight ruminally cannulated cows were used in a $4 \times 4$ Latin square design with 14-d periods. Cows were fed PMR once daily at 1200 $\mathrm{h}$, and pellet twice daily at 0600 and $1800 \mathrm{~h}$. Data and samples were collected on d 11 to 14 of each period. By design there was a difference in pellet intake between the $\mathrm{H}$ and $\mathrm{L}$ treatments (5.31 vs. $1.81 \mathrm{~kg} / \mathrm{d}$ ), and PMR intake was reduced when $\mathrm{H}$ pellet was fed (22.9 vs. $25.3 \mathrm{~kg} / \mathrm{d}$ ); however, feeding $\mathrm{H}$ tended to increase total dry matter intake. Feed disappearance, which was measured as the amount of PMR consumed every $3 \mathrm{~h}$ following PMR delivery, was affected by the nutrient composition of the PMR as cows fed S (with high-fiber PMR) consumed $28.6 \%$ of their PMR intake within $3 \mathrm{~h}$ of delivery, whereas cows fed $\mathrm{F}$ (with high-starch PMR) consumed $33.5 \%$. Duration that $\mathrm{pH}$ was below 5.8 tended to be lower when cows were fed the S pellet (270 vs. $125 \mathrm{~min} / \mathrm{d}$ ) compared with F. In addition, feeding the S pellet (with high-fiber PMR) decreased plasma concentrations of glucose $(66.0$ vs. $70.0 \mathrm{mg} / \mathrm{dL})$ and insulin (1.90 vs. $2.25 \mathrm{ng} / \mathrm{mL}$ ) compared with F. These results suggest that the composition of the PMR
\end{abstract}

Received October 3, 2019.

Accepted February 4, 2020

*Corresponding author: moba@uaberta.ca dictates rumen fermentation to a greater extent than composition of pellets. The S pellet was fed alongside a high-fiber PMR, which was more filling in the rumen, less fermentable, and contained more neutral detergent fiber. Although no difference was observed in milk production among treatments, the fact that feed intake pattern and rumen fermentation are better explained by nutrient composition of the PMR should be considered when formulating diets for lactating cows fed pellet and PMR, such as those milked with automated milking systems.

Key words: high-fiber pellet, high-starch pellet, rumen fermentation, feeding behavior

\section{INTRODUCTION}

Dairy cattle in North America are typically fed TMR where all feed ingredients are combined to deliver the same nutrients with every mouthful of feed. However, as automated milking systems (AMS) grow in popularity, there is a move back to component feeding, where a portion of the diet is fed as a concentrate in the AMS, and the remainder is fed at the bunk as a partial mixed ration (PMR). With this feeding management, it is common for the concentrate in the AMS to be delivered as a high-starch pellet to encourage voluntary visits to the AMS (Prescott et al., 1998; Bach and Cabrera, 2017).

A concern with offering a high-starch pellet is that its consumption in a short period of time may reduce rumen $\mathrm{pH}$, alter feed intake patterns, and decrease overall DMI. The effect of pellet feeding on PMR intake pattern is of interest for cows managed with AMS as milk production is affected by total DMI. Although a growing body of research indicates that it is not necessary to feed high amounts of pellet in the AMS to encourage voluntary visits (Hare et al., 2018; Henriksen et al., 2019; Paddick et al., 2019), little research has evaluated the effects of nutrient composition of pellet and nutrient allocation between the pellet and PMR on feeding behavior and rumen fermentation. Previous 
research has shown that feeding a high-starch pellet to dairy cows decreases DMI, number of meals, and eating duration of cows (Miron et al., 2004a,b) when fed through automatic feed stations, but does not affect milk production or number of milkings per day when implemented with AMS (Halachmi et al., 2006) as compared with a high-fiber pellet. Based on these findings, it would be acceptable to feed a high-fiber pellet to maximize DMI while maintaining milk production and number of milkings. However, in these studies, cows were fed the same PMR regardless of pellet type; thus, cows fed a high-starch pellet would have greater starch intake in their overall diet, in which effects of pellet type on rumen fermentation are confounded by effects of overall diet. Therefore, it is not known what effects a high-starch pellet would have when fed alongside a complementary PMR formulated to create a common overall diet and whether animal response to pellet type may be affected by the amount of pellet fed.

The objective of this experiment was to evaluate the effects of feeding a high-fiber or high-starch pellet at 2 feeding amounts on rumen fermentation, feeding behaviors, DMI, and milk production when fed alongside a complementary PMR. We hypothesized that feeding a high-starch pellet would decrease rumen $\mathrm{pH}$ compared with high-fiber pellet, which would reduce PMR intake following pellet consumption, thus reducing overall DMI, and that these effects would be more pronounced when greater amounts of pellet were fed.

\section{MATERIALS AND METHODS}

All procedures were preapproved by the Animal Care and Use Committee for Livestock at the University of Alberta (AUP \#2170) and conducted according to the guidelines of the Canadian Council of Animal Care (Ottawa, ON, Canada).

\section{Experimental Design, Diet, and Treatments}

All cows were fed a diet as a TMR, ad libitum, once daily at $1200 \mathrm{~h}$, allowing for $5 \%$ refusals during a 21 -d diet adaptation period. The diet was formulated to provide adequate ME and MP for a $650-\mathrm{kg}$ cow producing $40 \mathrm{~kg}$ of milk per day with a DMI of $25 \mathrm{~kg} / \mathrm{d}$ (NRC, 2001). Following this diet adaptation, a portion of the diet was removed and fed as a high-fiber (F; $33.2 \%$ NDF, $13.5 \%$ starch on a DM basis) or a high-starch (S; 8.3\% NDF, $56.8 \%$ starch on a DM basis) pellet, fed separately from the rest of the diet at a high $(\mathbf{H} ; 3 \mathrm{~kg}$ as-fed basis) or low (L; $1 \mathrm{~kg}$ as-fed basis) amount twice per day, resulting in 4 experimental treatments of $\mathrm{FH}$, FL, SH, and SL. Four complementary PMR were formulated such that the total diet provided to the cows (pellet + PMR) was the same among all treatments with a target DMI of $25 \mathrm{~kg} / \mathrm{d}$. The concentrate portion of each complimentary PMR was fed as a mash, with all ingredients ground. All ingredients in the pellets were ground before pelleting via steam conditioning at $170^{\circ} \mathrm{F}$ and using a pellet mill [California Pellet Mill (CPM) Model 3020, Western Process Equipment, Calgary AB, Canada] with a 9/64-in diameter. Pellets were stored in 20-kg bags and not exposed to augers, staying intact through handling. Each pellet and mash were produced from one batch at the beginning of the study to maintain consistency in particle size and formulation for the entirety of the study.

Pellets were fed twice per day to allow for a large pellet meal to induce more pulsatile rumen fermentation. A conceptual description of the dietary treatments is shown in Table 1, and ingredients and nutrient composition of each dietary treatment are shown in Table 2.

Eight multiparous Holstein cows fitted with ruminal cannulas (Bar Diamond Inc., Parma, ID) were used in a $4 \times 4$ Latin square design with 14 -d periods consisting of $10 \mathrm{~d}$ of experimental treatment adaptation and 4

Table 1. Experimental diets (\% of diet DM) containing a high-fiber (F) or high-starch pellet (S) fed separately from a partial mixed ration (PMR) at a high ( $\mathrm{H} ; 3 \mathrm{~kg}$, as-fed basis) or low (L; $1 \mathrm{~kg}$, as-fed basis) amount twice per day assuming DMI of $25 \mathrm{~kg} / \mathrm{d}^{1}$

\begin{tabular}{|c|c|c|c|c|}
\hline \multirow[b]{2}{*}{ Diet component, $\%$ of diet DM } & \multicolumn{4}{|c|}{ Treatment } \\
\hline & FH & FL & $\mathrm{SH}$ & SL \\
\hline \multicolumn{5}{|l|}{ Pellet } \\
\hline High-fiber pellet fed outside PMR & 21.2 & 7.2 & - & - \\
\hline High-fiber pellet fed within PMR & - & 14.0 & - & - \\
\hline High-starch pellet fed outside PMR & - & - & 21.2 & 7.2 \\
\hline High-starch pellet fed within PMR & - & - & - & 14.0 \\
\hline \multicolumn{5}{|l|}{ Basal PMR } \\
\hline Basal PMR for high-fiber pellet treatment & 78.8 & 78.8 & - & - \\
\hline Basal PMR for high-starch pellet treatment & - & - & 78.8 & 78.8 \\
\hline
\end{tabular}

${ }^{1}$ Actual diet component consumed by animals differed for those consuming more or less than $25 \mathrm{~kg} / \mathrm{d}$ of DMI because pellets fed outside PMR were limit fed, whereas basal PMR and pellets in PMR were fed ad libitum. 
Table 2. Ingredient and nutrient composition of the total diet, fiber (F) and starch (S) pellet, and their complementary partial mixed rations (PMR) when a high (3 kg, as-fed basis; $\mathrm{H})$ or low $(1 \mathrm{~kg}$, as-fed basis; L) amount of pellet was fed twice per day

\begin{tabular}{|c|c|c|c|c|c|c|c|}
\hline Item & Total diet & Pellet F & Pellet S & PMR FH & PMR FL & PMR SH & PMR SL \\
\hline \multicolumn{8}{|l|}{ Ingredient, $\%$ of $\mathrm{DM}$} \\
\hline Barley silage & 38.7 & & & 49.5 & 41.8 & 49.4 & 41.8 \\
\hline Barley grain & 12.5 & & 61.1 & 16.1 & 13.6 & & 8.9 \\
\hline Corn grain & 5.4 & & 26.2 & 6.9 & 5.8 & & 3.9 \\
\hline Wheat grain & 1.8 & 8.8 & 8.9 & & 1.3 & & 1.3 \\
\hline Canola meal & 6.1 & & & 7.8 & 6.6 & 7.8 & 6.6 \\
\hline Soybean meal & 6.1 & & & 7.8 & 6.6 & 7.8 & 6.6 \\
\hline Wheat:corn DDGS ${ }^{1}$ & 6.1 & & & 7.8 & 6.6 & 7.8 & 6.6 \\
\hline Vitamins and mineral mix ${ }^{2}$ & 2.8 & & & 3.6 & 3.0 & 3.6 & 3.0 \\
\hline \multicolumn{8}{|l|}{ Analyzed nutrient composition } \\
\hline$\%$ of DM & 48.8 & 91.2 & 89.7 & 55.8 & 59.6 & 47.8 & 51.9 \\
\hline $\mathrm{CP}, \%$ of $\mathrm{DM}$ & 17.3 & 13.7 & 11.7 & 17.3 & 16.4 & 17.9 & 17 \\
\hline \multicolumn{8}{|l|}{ Particle distribution of PMR, \% } \\
\hline Top $>19 \mathrm{~mm}$ & & & & 10.3 & 7.8 & 8.3 & 9.2 \\
\hline Middle 8-19 mm & & & & 35.3 & 33.4 & 33.4 & 31.2 \\
\hline Bottom $<8 \mathrm{~mm}$ & & & & 54.4 & 58.8 & 58.3 & 59.6 \\
\hline
\end{tabular}

${ }^{1}$ DDGS $=$ distillers dried grains with solubles.

${ }^{2}$ Contained $13.1 \mathrm{kIU} / \mathrm{kg}$ vitamin A, $1.4 \mathrm{kIU} / \mathrm{kg}$ vitamin D, $40.8 \mathrm{IU} / \mathrm{kg}$ vitamin E, $0.91 \mathrm{mg} / \mathrm{kg} \mathrm{Co,} 34.0 \mathrm{mg} / \mathrm{kg} \mathrm{Cu}, 79.4 \mathrm{mg} / \mathrm{kg} \mathrm{Mn}, 76.9 \mathrm{mg} / \mathrm{kg}$ $\mathrm{Zn}$, and $1.03 \mathrm{mg} / \mathrm{kg} \mathrm{Se}$.

$\mathrm{d}$ of sample collection. Pre-experiment DIM (mean \pm SD) was $115 \pm 21 \mathrm{~d}$. Cows were housed individually in tiestalls and milked twice daily at 0500 and 1700 $\mathrm{h}$. Pellet treatments were fed at 0600 and $1800 \mathrm{~h}$ and PMR was offered at $1200 \mathrm{~h}$ within 2 min after the previous day's orts were removed. Cows were fed PMR in individual feed mangers, and their treatment pellets in 8-quart duraflex rubber feed pans (Miller Manufacturing, Eagan, MN) separate from their feed mangers to avoid contamination of the PMR and given 10 min to consume the pellet.

\section{Data and Sample Collection}

The amount of pellet and PMR offered and refused was recorded for individual cows at the time of feeding, and the amount of PMR fed was adjusted daily to maintain 5\% refusals. Dietary ingredients were sampled on d 11 to 13 and composited for each period to determine chemical composition of the diet. All ingredient samples were dried for $72 \mathrm{~h}$ at $55^{\circ} \mathrm{C}$ in a forced-air oven and stored until further analysis. One-eighth of refused PMR was kept on d 11 to 13 and composited to yield one sample per cow per period to determine extent of sorting. Disappearance of PMR relative to its delivery was determined by weighing the amount of feed left every $3 \mathrm{~h}$ in individual feed mangers; cows were prevented from eating for 1 min while feed mangers were weighed in front of the stall with feed in them to minimize disruption of feeding behavior.

Milk yield was recorded at every milking and milk samples (approximately $40 \mathrm{~mL}$ ) were taken from 6 consecutive milkings from d 11 to 13 and stored at $4^{\circ} \mathrm{C}$ with 2-bromo-2-nitropropane-1,3-diol until milk composition analysis. Rumen $\mathrm{pH}$ was determined every $30 \mathrm{~s}$ from d 11 to 13 using the Lethbridge Research Centre Ruminal pH Measurement System (Dascor, Escondido, CA) and millivolt readings were converted to pH units as described by Penner et al. (2006). Duration of $\mathrm{pH}$ depression was calculated as the total number of minutes that rumen $\mathrm{pH}$ was below 5.8. Severity of $\mathrm{pH}$ depression was calculated as the area under the curve when $\mathrm{pH}$ was below 5.8, and acidosis index calculated as the severity of $\mathrm{pH}$ depression normalized for DMI (Gao and Oba, 2014).

On d 14, cows were fitted with jugular catheters (0.86 mm i.d. $\times 1.32 \mathrm{~mm}$ o.d.; Scientific Commodities Inc., Lake Havasu City, AZ) and blood samples were collected every $90 \mathrm{~min}$ for a 24 -h period, to account for diurnal variation in blood metabolite concentrations, beginning at PMR delivery. A 5-mL waste sample was removed before sample collection and catheters were flushed with $5 \mathrm{~mL}$ of heparinized saline ( $2 \%$ solution) following collection. Blood samples were collected using 
12-mL syringes and then placed into a sodium heparin vacutainer (BD Vacutainer, Franklin Lakes, NJ). Following collection, samples were immediately placed on ice before centrifugation at $3,000 \times g$ for 20 min at $4^{\circ} \mathrm{C}$; harvested plasma samples were stored at $-20^{\circ} \mathrm{C}$ until analysis.

\section{Sample Analysis}

Dried feed samples were ground through a 1-mm screen with a Wiley mill (Thomas-Wiley, Philadelphia, $\mathrm{PA}$ ) and sent to Cumberland Valley Analytical Services (Hagerstown, MD) for analysis of DM (AOAC International, 2002; method 930.15), OM (AOAC International, 2002; method 942.05), NDF (Van Soest et al., 1991), starch (Hall, 2009), and CP (AOAC International, 2002; method 990.03). Milk samples were individually analyzed for concentrations of milk fat, $\mathrm{CP}$, lactose, and MUN (AOAC International, 2002; method 972.16; MilkoScan 605, Foss North America, Brampton, ON, Canada) at the Alberta Central Milk Testing Laboratory (Edmonton, AB, Canada). Particle size distribution of the PMR and orts were determined using a Penn State Particle Separator with 2 sieves (aperture size of 19 and $8 \mathrm{~mm}$ ) and the bottom pan using the procedure described by Lammers et al, (1996). Sorting index was calculated as the ratio of actual intake to predicted intake for particles retained on each sieve of the separator, on an as-fed basis (Leonardi and Armentano, 2003). A sorting index of 100, greater than 100, and less than 100 indicate no sorting, selective consumption, and selective refusals of each particle portion of PMR, respectively.

Plasma samples were analyzed for concentrations of glucose and insulin. Plasma glucose concentration was determined using a glucose oxidase/peroxidase enzyme (no. P7119, Sigma Co., St. Louis, MO) and dianisidine dihydrochloride (no. F5803, Sigma Co.). Absorbance at $450 \mathrm{~nm}$ was determined using a SpectraMax 190 plate reader (Molecular Devices Corp., Sunnyvale, CA). Plasma insulin concentration was determined using a solid-phase competition immunoassay with Eu-labeled bovine insulin and polystyrene microtiter strips coated with anti-guinea pig $\gamma$-globin (Takahashi et al., 2006; Inabu et al., 2017). Strips were read using time resolved fluorometry (VictorX multi-plate reader, PerkinElmer Inc., Waltham, MA).

\section{Statistical Analysis}

Statistical analysis was completed using the FIT model of JMP (version 14, SAS Institute Inc., Cary, $\mathrm{NC}$ ) with the following model:

$$
\mathrm{Y}_{\mathrm{ijkl}}=\mu+\mathrm{C}_{\mathrm{i}}+\mathrm{A}_{\mathrm{j}}+\mathrm{CA}_{\mathrm{ij}}+\mathrm{P}_{\mathrm{k}}+\mathrm{H}_{\mathrm{l}}+\mathrm{e}_{\mathrm{ijk} \mathrm{k}},
$$

where $Y_{i j k l}$ is the dependent variable, $\mu$ is the overall mean, $C_{i}$ is the effects of type of concentrate pellet, $A_{j}$ is the amount of pellet fed, $\mathrm{CA}_{\mathrm{ij}}$ is the effect of interaction among type and amount of pellet, $\mathrm{P}_{\mathrm{k}}$ is the effect of period, $\mathrm{H}_{1}$ is the random effect of cow, and $\mathrm{e}_{\mathrm{ijk} \mathrm{l}}$ is the residual. Significance was declared when $P<0.05$ and tendencies were discussed when $P<0.10$.

\section{RESULTS}

During sampling, all cows were able to consume the pellet within 6 min of delivery. By design, cows fed $\mathrm{H}$ had greater pellet DMI than L $(5.31$ vs. $1.81 \mathrm{~kg} / \mathrm{d} ; P<$ 0.001; Table 3). Partial mixed ration DMI was reduced for cows fed $\mathrm{H}$ amount of pellet, regardless of the type fed (22.9 vs. $25.3 \mathrm{~kg} / \mathrm{d} ; P<0.001)$, as compared with L. Cows fed the $\mathrm{H}$ amount of pellet tended to increase total DMI (28.2 vs. $27.1 \mathrm{~kg} / \mathrm{d} ; P=0.08)$ compared with L. Feed disappearance recorded as the percentage of PMR intake consumed was higher for cows fed the $\mathrm{F}$ pellet in the $3 \mathrm{~h}$ after feed delivery (33.5 vs. $28.6 \%$ PMR intake; $P=0.04$; Figure 1) compared with the $\mathrm{S}$ pellet. There was a tendency for an interaction between pellet type and amount in sorting long particles $(>19$ $\mathrm{mm}$ ) of PMR (Table 3), but sorting indexes were not different from 100, indicating that animals did not sort PMR in the current study.

No difference was observed in minimum, mean, or maximum $\mathrm{pH}$ among treatments (Table 4). Feeding the $\mathrm{F}$ pellet tended to increase the duration that $\mathrm{pH}$ was below $5.8(196$ vs. $126 \mathrm{~min} / \mathrm{d} ; P=0.08)$ and the acidosis index (1.68 vs. $0.78 \mathrm{pH} \times \min / \mathrm{DMI} ; P=0.09)$ compared with the $\mathrm{S}$ pellet. Feeding the $\mathrm{L}$ amount of pellet tended to increase duration that $\mathrm{pH}$ was below 5.8 (197 vs. $124 \mathrm{~min} / \mathrm{d} ; P=0.06$ ) and severity of rumen $\mathrm{pH}$ depression (44.8 vs. $24.2 \mathrm{pH} \times \min / \mathrm{d} ; P=0.06)$ compared with $\mathrm{H}$. Rumen $\mathrm{pH}$ over a 24 -h period is shown in Figure 2. No difference was observed in milk yield $(42.6 \mathrm{~kg})$ or components among treatments (Table $5)$.

Feeding the $\mathrm{F}$ pellet increased plasma concentrations of glucose $(70.0$ vs. $66.0 \mathrm{mg} / \mathrm{dL} ; P<0.01$; Table 6$)$ and insulin (2.25 vs. $1.9 \mathrm{ng} / \mathrm{mL} ; P=0.02)$ compared with $\mathrm{S}$, regardless of amount.

\section{DISCUSSION}

Controlled research studies evaluating feeding strategies for AMS have found that large concentrate allowances in the AMS do not increase voluntary visits or milk production (Bach et al., 2007; Hare et al., 2018; 
Table 3. The effects of feeding a high-fiber (F) or high-starch (S) pellet at a high (3 kg, as-fed basis; H) or low (1 kg, as-fed basis; L) quantity twice per day on DMI and sorting behaviors of mid-lactation dairy cows

\begin{tabular}{|c|c|c|c|c|c|c|c|c|}
\hline \multirow[b]{2}{*}{ Item } & \multicolumn{4}{|c|}{ Treatment } & \multirow[b]{2}{*}{ SEM } & \multicolumn{3}{|c|}{$P$-value ${ }^{1}$} \\
\hline & FH & FL & $\mathrm{SH}$ & $\mathrm{SL}$ & & $\mathrm{CHO}$ & $\mathrm{AMT}$ & $\mathrm{CHO} \times \mathrm{AMT}$ \\
\hline Partial mixed ration DMI, $\mathrm{kg} / \mathrm{d}$ & 22.2 & 25.2 & 23.7 & 25.5 & 0.85 & 0.12 & $<0.001$ & 0.30 \\
\hline Total DMI, $\mathrm{kg} / \mathrm{d}$ & 27.4 & 27.0 & 29.1 & 27.3 & 0.89 & 0.11 & 0.08 & 0.25 \\
\hline \multicolumn{9}{|l|}{ Sorting index } \\
\hline Top >19 mm & 103.9 & 97.4 & 99.1 & 104.9 & 3.3 & 0.68 & 0.91 & 0.08 \\
\hline
\end{tabular}

${ }^{1} \mathrm{CHO}=$ type of carbohydrate (high fiber or high starch); AMT = amount of pellet fed (high or low).

Henriksen et al., 2018; Paddick et al., 2019). However, survey data from industry indicate that programmed amounts of concentrate fed through the AMS range from 0.9 to $11.3 \mathrm{~kg}$ per cow per day (Salfer and Endres, 2014), with $22 \%$ of Canadian farms offering more than $5.0 \mathrm{~kg}$ per cow per day (de Jong et al., 2003). A possible concern is that cows provided a large meal of a high-starch concentrate during milking in the AMS may return to the stalls and not be motivated to move to the feed bunk as frequently. If this happens, total DMI as well as milk production may decrease. Although previous research has shown that it is possible to use a high-fiber pellet to attract cows to an AMS (Halachmi et al., 2006), little is known about the effects of feeding a high-fiber pellet on rumen fermentation and feed intake patterns. Therefore, the objective of this experiment was to evaluate the effects of feeding a high-fiber or high-starch pellet at a high or low amount on rumen fermentation and feed intake pattern when

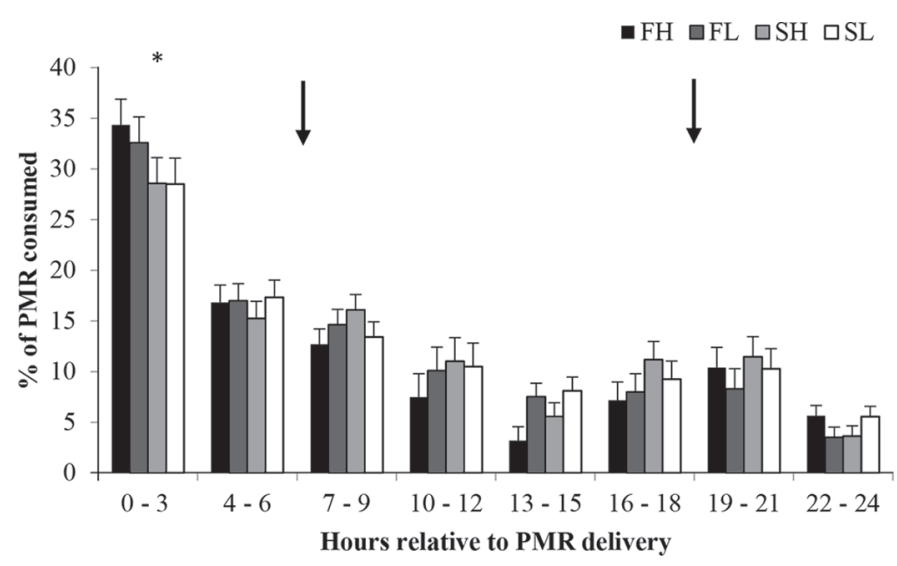

Figure 1. Feed disappearance pattern of partial mixed ration (PMR) when cows were fed a high-fiber (F) or high-starch (S) pellet at a high $(\mathrm{H})$ or low $(\mathrm{L})$ amount. Arrows indicate when pellet was fed relative to PMR delivery. ${ }^{*}$ Cows fed the $\mathrm{S}$ pellet had lower PMR intake in the first $3 \mathrm{~h}$ after PMR delivery $(P=0.04)$. Error bars denote SEM. fed alongside a complementary PMR, in a simulated AMS setting.

The current study was conducted in a tiestall facility with pellet fed separately from the PMR twice per day. By conducting the experiment in a tiestall facility, we were able to determine the specific effects of pellet type and feeding amount on rumen fermentation and feed intake pattern in an environment where cows can stand, lie, or eat whenever they want, thus minimizing confounding factors such as stall design, flooring, stocking density, or competition for feed that may be seen in a freestall facility. While we acknowledge that the current study has limitations as cows are not exposed to the aforementioned variables and group dynamics, and not milked with an AMS, we think that the principles of our findings are applicable to nutritional management for cows managed with an AMS.

\section{High-Starch vs. High-Fiber Pellet}

Previous studies evaluating effects of component feeding have shown that as concentrate intake increases, PMR intake is reduced (Bach et al., 2007; Hare et al., 2018; Henriksen et al., 2018, 2019; Menajovsky et al., 2018), which is in alignment with our findings. In these studies, the extent to which PMR intake is reduced with an additional unit increase in concentrate allowance is inconsistent, therefore total DMI may or may not be reduced. The reduction in forage or PMR DMI per unit of additional concentrate intake is called the substitution rate (Faverdin et al., 1991). In the current study, the calculated substitution rate was 0.88 and 0.50 for the $\mathrm{F}$ and $\mathrm{S}$ pellet, respectively, meaning that for every 1-kg increase in F pellet DMI, PMR DMI was reduced by $0.88 \mathrm{~kg}$, whereas when the $\mathrm{S}$ pellet was fed a $1-\mathrm{kg}$ increase in S pellet DMI reduced PMR DMI by $0.50 \mathrm{~kg}$.

The exact mechanism behind how cows substitute intake among concentrate and forage or PMR is unknown (Jensen et al., 2016). Older literature evaluating the 
Table 4. The effects of feeding a high-fiber (F) or high-starch (S) pellet at a high (3 kg, as-fed basis; H) or low (1 kg, as-fed basis; L) quantity twice per day on rumen $\mathrm{pH}$ of mid-lactation dairy cows

\begin{tabular}{|c|c|c|c|c|c|c|c|c|}
\hline \multirow[b]{2}{*}{ Ruminal pH } & \multicolumn{4}{|c|}{ Treatment } & \multirow[b]{2}{*}{ SEM } & \multicolumn{3}{|c|}{$P$-value ${ }^{1}$} \\
\hline & $\mathrm{FH}$ & FL & $\mathrm{SH}$ & SL & & $\mathrm{CHO}$ & AMT & $\mathrm{CHO} \times \mathrm{AMT}$ \\
\hline Mean & 6.18 & 6.15 & 6.22 & 6.18 & 0.05 & 0.39 & 0.33 & 0.85 \\
\hline Maximum & 6.88 & 7.06 & 7.06 & 7.22 & 0.11 & 0.19 & 0.19 & 0.93 \\
\hline Duration $\mathrm{pH}<5.8, \mathrm{~min} / \mathrm{d}$ & 147 & 245 & 101 & 150 & 60.5 & 0.08 & 0.06 & 0.49 \\
\hline Area $\mathrm{pH}<5.8(\mathrm{pH} \times \min / \mathrm{d})$ & 29 & 57 & 19 & 33 & 13.7 & 0.12 & 0.06 & 0.49 \\
\hline
\end{tabular}

${ }^{1} \mathrm{CHO}=$ type of carbohydrate (high fiber or high starch); AMT = amount of pellet fed (high or low).

substitution rate when dairy cows were fed concentrate separately from forage found that feeding a high-starch concentrate had a higher substitution rate compared with a high-fiber concentrate (Faverdin et al., 1991), which contrasts with the results observed in the current study. However, it is important to note that Faverdin et al. (1991) did not feed concentrate alongside a PMR but rather concentrate separate to silage only, and the amount of concentrate accounted for up to $50 \%$ of total DMI. In the current study and other recent studies evaluating substitution rate (Menajovsky et al., 2018; Paddick et al., 2019), the amount of concentrate
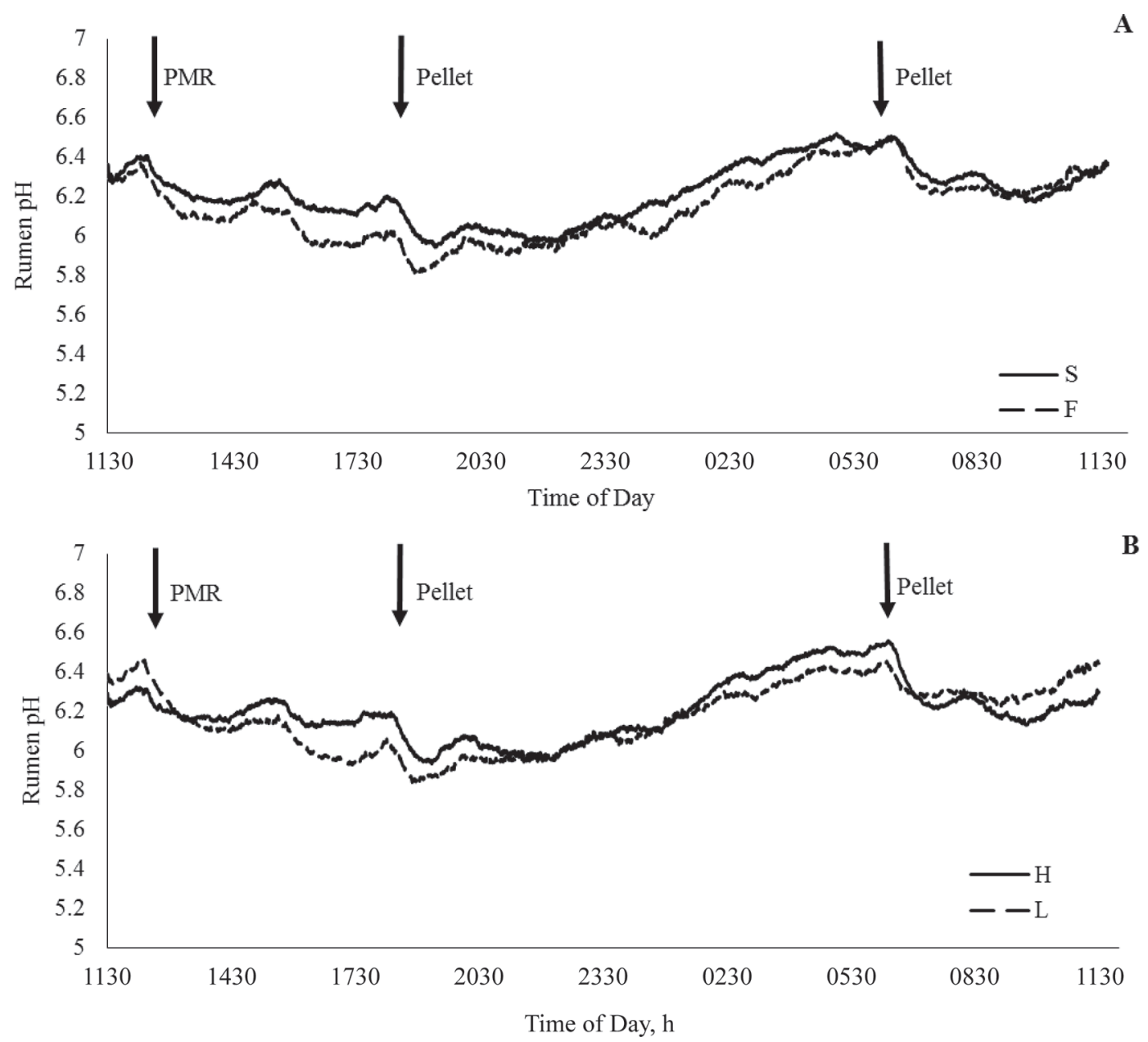

Figure 2. Rumen pH over a 24-h period beginning 30 min before partial mixed ration (PMR) delivery of a high-fiber (F) or high-starch (S) pellet (panel A) or at a high (H) or low (L) amount (panel B). 
Table 5. The effects of feeding a high-fiber (F) or high-starch (S) pellet at a high (3 kg, as-fed basis; H) or low $(1 \mathrm{~kg}$, as-fed basis; L) quantity twice per day on milk production of mid-lactation dairy cows

\begin{tabular}{|c|c|c|c|c|c|c|c|c|}
\hline \multirow[b]{2}{*}{ Item } & \multicolumn{4}{|c|}{ Treatment } & \multirow[b]{2}{*}{ SEM } & \multicolumn{3}{|c|}{$P$-value ${ }^{1}$} \\
\hline & FH & FL & $\mathrm{SH}$ & SL & & $\mathrm{CHO}$ & AMT & $\mathrm{CHO} \times \mathrm{AMT}$ \\
\hline Milk, kg/d & 42.5 & 42.9 & 42.1 & 42.9 & 1.0 & 0.67 & 0.22 & 0.59 \\
\hline Fat, $\%$ & 3.70 & 3.70 & 3.62 & 3.68 & 0.07 & 0.29 & 0.51 & 0.57 \\
\hline Protein, \% & 3.25 & 3.24 & 3.26 & 3.24 & 0.03 & 0.82 & 0.16 & 0.72 \\
\hline Lactose, \% & 4.59 & 4.60 & 4.59 & 4.60 & 0.04 & 0.70 & 0.66 & 0.97 \\
\hline Fat, $\mathrm{kg} / \mathrm{d}$ & 1.57 & 1.59 & 1.52 & 1.58 & 0.07 & 0.65 & 0.59 & 0.59 \\
\hline Protein, $\mathrm{kg} / \mathrm{d}$ & 1.38 & 1.39 & 1.37 & 1.39 & 0.03 & 0.76 & 0.70 & 0.57 \\
\hline Lactose, $\mathrm{kg} / \mathrm{d}$ & 1.97 & 1.97 & 1.94 & 1.98 & 0.05 & 0.78 & 0.38 & 0.39 \\
\hline MUN, mg/mL & 13.2 & 13.5 & 13.6 & 12.6 & 0.7 & 0.60 & 0.50 & 0.22 \\
\hline
\end{tabular}

${ }^{1} \mathrm{CHO}=$ type of carbohydrate (high fiber or high starch); AMT = amount of pellet fed (high or low).

accounted for less of the total diet and concentrate was fed alongside a PMR containing both forage and concentrate.

In the current study, cows were fed complementary PMR as an effort to make the overall diet similar in nutrient composition among all treatments, which may account for some discrepancies because there were no negative effects of feeding the $\mathrm{S}$ pellet on rumen fermentation or feed disappearance following pellet feeding. It has recently been hypothesized that the substitution rate of PMR for concentrate is dependent upon the energy content of the PMR rather than the concentrate itself, with greater substitution when a high-energy PMR is fed (Hendriksen et al., 2018). In the current study, when the F pellet was fed, the complementary PMR was high in starch and when the $\mathrm{S}$ pellet was fed, the complementary PMR was high fiber; thus, our findings regarding substitution rate are in alignment with the proposed hypothesis that the energy content of the PMR may influence substitution rate rather than the type of pellet fed.

Before this study, we had hypothesized that feeding $\mathrm{S}$ pellet would reduce rumen $\mathrm{pH}$ following consumption, thus supressing feed intake in the period after pellet feeding. Contrary to this hypothesis, feeding $\mathrm{S}$ pellet tended to reduce the duration that $\mathrm{pH}$ was below 5.8 and the severity of $\mathrm{pH}$ depression. We observed no difference in feed intake pattern relative to pellet de- livery. It is well established that feeding a high-starch TMR increases the risk of ruminal acidosis, and the animal responses observed with the F pellet (fed with high-starch PMR) are consistent with those fed a highstarch TMR. In the first $3 \mathrm{~h}$ following PMR delivery, the amount of starch consumed through PMR for FH and FL was 2.1 and $1.8 \mathrm{~kg}$, whereas SH and SL consumed 0.96 and $1.4 \mathrm{~kg}$ of starch, respectively. The dose of starch from the PMR fed alongside the $\mathrm{S}$ pellet is less than the $1.5-\mathrm{kg}$ dose obtained with the $\mathrm{SH}$ treatment. Therefore, feeding starch through a controlled dose may act to regulate rumen $\mathrm{pH}$ when fed alongside a high-fiber PMR.

Cows consumed 28 to $35 \%$ of their total PMR intake within the first $3 \mathrm{~h}$ after PMR delivery, which is in alignment with previous research. Feed delivery has been shown to be the primary driver of feed intake when feeding a TMR (DeVries et al., 2005; DeVries and von Keyserlingk, 2005), and previous research comparing feeding a TMR versus a PMR plus pellet at $9.5 \%$ of DMI found that feeding the pellet $1 \mathrm{~h}$ before feed delivery did not influence intake patterns of dairy cows (Niu and Harvatine, 2018).

However, feed intake in the $3 \mathrm{~h}$ after PMR delivery was reduced when the $\mathrm{S}$ pellet was fed as compared with the $\mathrm{F}$ pellet. We speculate that the greater fiber content of the PMR fed with the S pellet increased reticulo-rumen fill, thus reducing intake during the first

Table 6. The effects of feeding a high-fiber (F) or high-starch (S) pellet at a high (3 kg, as-fed basis; $\mathrm{H})$ or low $(1 \mathrm{~kg}$, as-fed basis; L) quantity twice per day on plasma glucose and insulin concentrations of mid-lactation dairy cows

\begin{tabular}{|c|c|c|c|c|c|c|c|c|}
\hline \multirow[b]{2}{*}{ Item } & \multicolumn{4}{|c|}{ Treatment } & \multirow[b]{2}{*}{ SEM } & \multicolumn{3}{|c|}{$P$-value ${ }^{1}$} \\
\hline & $\mathrm{FH}$ & FL & $\mathrm{SH}$ & SL & & $\mathrm{CHO}$ & $\mathrm{AMT}$ & $\mathrm{CHO} \times \mathrm{AMT}$ \\
\hline Plasma glucose, mg/dL & 69.6 & 70.3 & 66.6 & 65.4 & 1.35 & $<0.01$ & 0.86 & 0.50 \\
\hline Plasma insulin, ng/mL & 2.0 & 2.5 & 1.9 & 1.9 & 0.14 & 0.02 & 0.11 & 0.09 \\
\hline
\end{tabular}

${ }^{1} \mathrm{CHO}=$ type of carbohydrate (high fiber or high starch); AMT = amount of pellet fed (high or low). 
$3 \mathrm{~h}$ after feed delivery. Although differences were not observed in feed disappearance at each of the other 3-h periods of the day, PMR consumption during the remaining period of the day must have increased for cows fed S compared with F pellet because PMR intake was not affected by pellet type. Extrapolating these findings to an AMS setting, there may be an advantage to feeding a S pellet alongside a high-fiber PMR because there were no negative effects on rumen fermentation and there may be the possibility for an increase in cow movement in the barn as cows may be motivated to consume PMR more evenly throughout the day, and this should be investigated further.

In addition, glucose and insulin concentrations were increased when the $\mathrm{F}$ pellet was fed. The high-starch PMR, fed alongside the F pellet, is expected to increase rumen starch fermentation, which would increase plasma concentrations of glucose and insulin following consumption (Reynolds, 2006). We speculate that the effects observed in the current study are better attributed to nutrient composition of PMR rather than pellet type because when a S pellet was fed, the PMR was high fiber, and when a $\mathrm{F}$ pellet was fed, a high-starch PMR was fed. It should be noted that the overall diet was relatively low in starch content due to the experimental design, where we needed to use high-fiber feedstuffs for $\mathrm{F}$ pellet, as well as feeding low-starch barley silage. Therefore, the results observed may be different when an overall diet is higher in starch content.

\section{High vs. Low Amount of Pellet}

We hypothesized that feeding $\mathrm{H}$ amounts of pellet would reduce rumen $\mathrm{pH}$, modifying feed intake patterns and reducing DMI. In addition, we expected that cows fed $\mathrm{H}$ would have lower total DMI as the PMR fed was higher in forage NDF and more filling than the PMR fed to L cows. However, feeding $\mathrm{H}$ did not reduce rumen $\mathrm{pH}$ or modify intake patterns, but tended to decrease duration and severity rumen $\mathrm{pH}$ depression. In addition, cows consumed more PMR than expected with a substitution rate of less than 1.0 regardless of pellet type, and overall DMI tended to be higher for cows fed $\mathrm{H}$.

There are inconsistencies in the literature when cows are fed a high or low amount of concentrate through an AMS and its effect on total DMI. Bach et al. (2007) and Hare et al. (2018) both reported a reduction in PMR intake when a high amount of concentrate was offered to cows housed with AMS. In both studies, PMR intake was reduced and the substitution ratio was greater than 1, resulting in the reduction in total DMI.
In both studies, feeding a high amount of concentrate reduced meal size, and Hare et al. (2018) reported a reduction in eating time with high concentrate allowance. Although it was not measured, Hare et al. (2018) speculated that feeding a high amount of concentrate and the modification in feed eating behavior reduced rumen $\mathrm{pH}$, thus causing a reduction in DMI. However, Paddick et al. (2019) conducted a similar study and found that increasing AMS concentrate from 0.5 to $5.0 \mathrm{~kg} / \mathrm{d}$ did not affect DMI and that the substitution ratio was 0.94 as concentrate allocation increased. In this study, the PMR was adjusted such that target nutrient intake was same when the pellet and PMR were considered. While there is no clear indication as to factors affecting DMI when an increased amount of concentrate is fed, it is likely that there are animal characteristics that influence animal responses such as DIM, availability of feed, and animal group dynamics. For example, in the studies conducted by Bach et al. (2007) and Hare et al. (2018), cows were in late lactation, whereas Paddick et al. (2019) used mid-lactation cows, which may explain the difference in substitution rate and DMI among the studies.

In the current study, we were able to control factors such as feed availability and group dynamics by using a tiestall facility. In the current study, feed intake pattern was not affected relative to pellet feeding times or the amount of pellet fed. Feeding an $\mathrm{H}$ amount of pellet tended to reduce the duration and severity of ruminal $\mathrm{pH}$ depression, likely due to the increased amount of forage NDF in the PMR fed alongside the $\mathrm{H}$ treatment. Therefore, it is likely that total DMI was not limited by rumen fill but rather by rumen $\mathrm{pH}$ in the current study as feeding the low forage PMR associated with an L amount of pellet tended to increase duration and severity of ruminal $\mathrm{pH}$ depression, resulting in a tendency for decreased DMI.

In the current study, despite the greater forage content of PMR with the $\mathrm{L}$ treatment, the sorting indexes were not different from 100, indicating that cows did not exhibit sorting behavior. The PMR fed had 9.3 and $7.7 \%$ of the diet retained on the top screen for the $\mathrm{H}$ and $\mathrm{L}$ treatment, respectively, so it is likely that cows were unable to sort the PMR due to uniformity of each PMR and lack of long particles. It should be noted that there are no clear recommendations for particle size distribution of a PMR. Although one can deduce that if concentrate is removed from the PMR, there should be a shift in proportions found on each screen, with an increase in longer particles, it is unclear as to the extent this shift should be and the implications it may have. Thus, guidelines for PMR are challenging as a PMR 
is often formulated to be high in NDF and provide moderate energy and nutrient requirements, without encouraging sorting due to an increase in long particles.

Even though treatment effects were detectible on rumen $\mathrm{pH}$, blood metabolites, and total DMI, no difference was observed in milk yield or components among treatments. The differences might not be large enough to elicit a milk production or component response with the Latin square design used. In addition, caution should be used when evaluating the milk production data due to the low number of experimental units and insufficient statistical power to detect the differences.

\section{CONCLUSIONS}

Feeding a high-starch pellet alongside a complementary high-fiber PMR reduced the duration that rumen $\mathrm{pH}$ was below 5.8 and did not affect feed intake patterns or total DMI of mid-lactation dairy cows. In addition, feeding a high amount of pellet, regardless of type, tended to decrease the duration and severity of rumen $\mathrm{pH}$ depression and increase DMI. Results from many of the measured variables indicate that the composition of the PMR may have a greater influence on feeding behaviors and rumen fermentation than the type of pellet fed. However, animal responses may be different if a common PMR was fed and the overall diet was different between pellet types. Nonetheless, based on this experimental design and findings, it would be suitable to feed a high-starch pellet at $6 \mathrm{~kg} / \mathrm{d}$, as fed, to midlactation dairy cows, and emphasis should be placed on the PMR when formulating diets for lactating dairy cows fed a pellet alongside PMR.

\section{ACKNOWLEDGMENTS}

The authors gratefully acknowledge financial support by Alberta Milk (Edmonton, AB, Canada) and the Natural Sciences and Engineering Research Council of Canada (Ottawa, ON, Canada). The authors have not stated any conflicts of interest.

\section{REFERENCES}

AOAC International. 2002. Official Methods of Analysis. 17th ed. 1st rev. AOAC Int., Gaithersburg, MD.

Bach, A., and V. Cabrera. 2017. Robotic milking: Feeding strategies and economic returns. J. Dairy Sci. 100:7720-7728. https://doi .org/10.3168/jds.2016-11694.

Bach, A., C. Iglesias, S. Calsamiglia, and M. Devant. 2007. Effect of amount of concentrate offered in automatic milking systems on milking frequency, feeding behavior, and milk production of dairy cattle consuming high amounts of corn silage. J. Dairy Sci. 90:5049-5055. https://doi.org/10.3168/jds.2007-0347.

de Jong, W., A. Finnema, and D. J. Reinemann. 2003. Survey of management practices of farms using automatic milking systems in North America. ASAE Annual International Meeting Technical Paper No. 033017. Am. Soc. Agric. Biol. Eng., St. Joseph, MI.

DeVries, T. J., and M. A. von Keyserlingk. 2005. Time of feed delivery affects the feeding and lying patterns of dairy cows. J. Dairy Sci. 88:625-631. https://doi.org/10.3168/jds.S0022-0302(05)72726-0.

DeVries, T. J., M. A. G. von Keyserlingk, and K. A. Beauchemin. 2005. Frequency of feed delivery affects the behavior of lactating dairy cows. J. Dairy Sci. 88:3553-3562. https://doi.org/10.3168/ jds.S0022-0302(05)73040-X.

Faverdin, P., J. P. Dulphy, J. B. Coulon, R. Vérité, J. P. Garel, J. Rouel, and B. Marquis. 1991. Substitution of roughage by concentrates for dairy cows. Livest. Prod. Sci. 27:137-156. https://doi .org/10.1016/0301-6226(91)90092-5.

Gao, X., and M. Oba. 2014. Relationship of severity of subacute ruminal acidosis to rumen fermentation, chewing activities, sorting behavior, and milk production in lactating dairy cows fed a highgrain diet. J. Dairy Sci. 97:3006-3016. https://doi.org/10.3168/ jds.2013-7472.

Halachmi, I., E. Shoshani, R. Solomon, E. Maltz, and J. Miron. 2006. Feeding of pellets rich in digestible neutral detergent fibre to lactating cows in an automatic milking system. J. Dairy Sci. 89:32413249. https://doi.org/10.3168/jds.S0022-0302(06)72599-1.

Hall, M. B. 2009. Analysis of starch, including malt oligosaccharides, in animal feeds: A comparison of methods and a recommended method for AOAC collaborative study. J. AOAC Int. 92:42-49.

Hare, K., T. J. DeVries, K. S. Schwartkopf-Genswein, and G. B. Penner. 2018. Does the location of concentrate provision affect voluntary visits, and milk and milk component yield for cows in an automated milking system? Can. J. Anim. Sci. 98:399-404. https: //doi.org/10.1139/cjas-2017-0123.

Henriksen, J. C. S., L. Munksgaard, and M. R. Weisbjerg. 2018 Short-term responses in production and behavior during periods of change in concentrate allowance of dairy cows. J. Dairy Sci. 101:7942-7953. https://doi.org/10.3168/jds.2018-14624.

Henriksen, J. C. S., M. R. Weisbjerg, P. Lovendahl, T. Kristensen, and L. Munksgaard. 2019. Effects of an individual cow concentrate strategy on production and behavior. J. Dairy Sci. 102:2155-2172. https://doi.org/10.3168/jds.2018-15477.

Inabu, Y., A. Saegusa, K. Inouchi, S. Koike, M. Oba, and T. Sugino. 2017. Plasma concentrations of glucagon-like peptide 1 and 2 in calves fed calf starters containing lactose. J. Dairy Sci. 100:93619371. https://doi.org/10.3168/jds.2017-12910.

Jensen, L. M., B. Markussen, N. I. Nielsen, E. Nadeau, M. R. Weisbjerg, and P. Norgaard. 2016. Description and evaluation of a net energy intake model as a function of dietary chewing index. J. Dairy Sci. 99:8699-8715. https://doi.org/10.3168/jds.2015-10389.

Lammers, B. P., D. R. Buckmaster, and A. J. Heinrichs. 1996. A simple method for the analysis of particle sizes of forage and total mixed rations. J. Dairy Sci. 79:922-928. https://doi.org/10.3168/ jds.S0022-0302(96)76442-1.

Leonardi, C., and L. E. Armentano. 2003. Effect of quantity, quality, and length of alfalfa hay on selective consumption by dairy cows. J. Dairy Sci. 86:557-564. https://doi.org/10.3168/jds.S0022 $-0302(03) 73634-0$

Menajovsky, S. B., C. E. Walpole, T. J. DeVries, K. S. SchwartzkopfGenswein, M. E. Walpole, and G. B. Penner. 2018. The effect of the forage-to-concentrate ratio of the partial mixed ration and the quantity of concentrate in an automatic milking system for lactating Holstein cows. J. Dairy Sci. 101:9941-9953. https://doi.org/10 $.3168 /$ jds.2018-14665.

Miron, J., M. Nikbachat, A. Zenou, D. Ben-Ghedalia, R. Solomon, E. Shoshani, I. Halachmi, N. Livshin, A. Antler, and E. Maltz. 2004a. Lactation performance and feeding behavior of dairy cows supplemented via automatic feeders with soy hulls or barley based pellets. J. Dairy Sci. 87:3808-3815. https://doi.org/10.3168/jds .S0022-0302(04)73520-1.

Miron, J., E. Yosef, M. Nikbachat, A. Zenou, E. Maltz, I. Halchemi, and D. Ben-Ghedalia. 2004b. Feeding behavior and performance of dairy cows fed pelleted nonroughage fibre byproducts. J. Dairy Sci. 87:1372-1379. https://doi.org/10.3168/jds.S0022 -0302(04)73286-5. 
Niu, M., and K. J. Harvatine. 2018. The effects of feeding a partial mixed ration plus a top-dress before feeding on milk production and the daily rhythm of feed intake and plasma hormones and metabolites in dairy cows. J. Dairy Sci. 101:164-171. https://doi .org/10.3168/jds.2017-13482.

NRC (National Research Council). 2001. Nutrient Requirements of Dairy Cattle. 7th ed. National Academy Press, Washington, DC.

Paddick, K. S., T. J. DeVries, K. Schwartzkopf-Genswein, M. A. Steele, M. E. Walpole, and G. B. Penner. 2019. Effect of the amount of concentrate offered in an automated milking system on dry matter intake, milk yield, milk composition, ruminal digestion, and behavior of primiparous Holstein cows fed isocaloric diets. J. Dairy Sci. 102:2173-2187. https://doi.org/10.3168/jds.2018-15138.

Penner, G. B., K. A. Beauchemin, and T. Mutsvangwa. 2006. An evaluation of the accuracy and precision of a stand-alone submersible continuous ruminal $\mathrm{pH}$ measurement system. J. Dairy Sci. 89:2132-2140. https://doi.org/10.3168/jds.S0022-0302(06)72284 $-6$.

Prescott, N. B., T. T. Mottram, and A. J. F. Webster. 1998. Effect of food type and location on the attendance to an automatic milking system by daily cows and the effect of feeding during milking on their behaviour and milking characteristics. Anim. Sci. 67:183193. https://doi.org/10.1017/S1357729800009942.

Reynolds, C. K. 2006. Production and metabolic effects of site of starch digestion in dairy cattle. Anim. Feed Sci. Technol. 130:7894. https://doi.org/10.1016/j.anifeedsci.2006.01.019.

Salfer, J., and M. Endres. 2014. How are robotic milking dairies feeding their cows? Pages 77-80 in Proc. 4-State Dairy Nutrition Conference, Dubuque, IA.

Takahashi, H., Y. Kurose, S. Kobayashi, T. Sugino, M. Kojima, K. Kangawa, Y. Hasegawa, and Y. Terashima. 2006. Ghrelin enhances glucose-induced insulin secretion in scheduled meal-fed sheep. J. Endocrinol. 189:67-75. https://doi.org/10.1677/joe.1.06310.

Van Soest, P. J., J. B. Robertson, and B. A. Lewis. 1991. Methods for dietary fiber, neutral detergent fiber, and nonstarch polysaccharide in relation to animal nutrition. J. Dairy Sci. 74:3583-3597.

\section{ORCIDS}

M. Oba @ https://orcid.org/0000-0001-8057-3500 